\title{
Using the IEEE 802.11 Family of Standards for Communication Between Robotic Systems
}

\author{
Andrei Vladyko, Alexander Paramonov, Ruslan Kirichek ${ }^{*}$ and Andrey Koucheryavy \\ The Bonch-Bruevich State University of Telecommunications, 22 Prospekt Bolshevikov, St. Petersburg, Russia \\ ${ }^{*}$ Corresponding author
}

\begin{abstract}
The paper analyzes the possibility of using the IEEE 802.11 standards for communication between the elements of robotic systems in terms of radio frequency (RF) channels congestion exterior traffic.
\end{abstract}

Keywords-robotic systems; communication; monitoring; frame; distribution

\section{INTRODUCTION}

This The development of IT in terms of construction machinery control systems leads to the intensive development of cybernetic devices and robots used in various fields of economic activity [1-5]. In most applications of robots and robotic systems the organization of communication between its elements is required. To ensure mobility of the system elements, various technology of wireless communication is usually used [6-11]. Communication between elements should be capable of transmitting a control signal, as the monitoring data, including images and video. To solve the tasks of interactive control of mechanisms, specific timing requirements for the delivery and control of monitoring data are shown. Meanwhile the bandwidth link between the elements of the system should provide the transfer of video and other data. To implement the radio channel, which satisfies these requirements, often standard solutions using unlicensed portions of RF spectrum are chosen. The most commonly solution is to use the IEEE 802.11 family of standards, which have the potential to ensure the completion of requirements on bandwidth. This family of standards is widely used for the organization of PAN-scale networks, and with the increasing number of devices that support them, this section of RF spectrum is used extensively (smartphones, tablets, TV receivers and other consumer electronics). For that matter, it is appropriate to evaluate the potential use of these technologies for communication between elements of the robotic system in dense urban environment where the probability of the use of a radio channel by external systems can be large enough to significantly reduce the channel bandwidth. With this aim, the research was conducted using the characteristics of standard IEEE 802.11 channels in urban dense environment.

\section{THE EXPERIMENTAL CONDITIONS}

A radio channel condition depends on many factors, depending on the localization of a transceiver device, environment, interference sources and its use by exterior devices. The degree of influence of each of these factors is determined by the specific conditions of use, however, as the characteristics of a radio channel use in an urban dense environment, statistical evaluations can be used, obtained for typical conditions [12]. In this study, as these conditions, the urban environment is considered, also it is assumed that the target system is mobile, and its speed of movement is comparable to walking pace. Therefore the move scenario in an urban environment with the average walking speed (3.8 $\mathrm{km} / \mathrm{h}$ ) was selected for study. As for movement trajectory, a random route was selected through the residential, business and mixed zone. Length of the route was $10.5 \mathrm{~km}$ and time of passage of the route - $2 \mathrm{~h} 48 \mathrm{~min}$, the average speed - $3.8 \mathrm{~km} / \mathrm{h}$.

With the passage of the route, registration of features use of standarts' channels IEEE 802.11 is performed. Preliminary analysis of channel utilization showed that the current high degree of use is typical for $2.4 \mathrm{GHz}$ channels. Therefore, for further analysis this range is selected.

Selection of technical means for obtaining statistical assessments was performed on the assumption that they have the characteristics in part of the transmit and receive data close to the characteristics of currently mass-produced devices. As the registration mean, a module based on microcontroller ESP8266 was chosen [13], allowing the implementation of additional user-defined functions with the software [14,15]. To implement the functions of statistics collection, program has been developed that provides monitoring of IEEE $802.11 \mathrm{~b} / \mathrm{g} / \mathrm{n}$ standards for wireless networks in the frequency range 2.4 $\mathrm{GHz}$. The device is placed in a shielded enclosure and is equipped with a standard external whip antenna.

\section{A. Use Indicators}

To characterize the channels usage of examined standards, the following parameters were selected: the number of networks (access points), the rate of the frame data transmission rate and the signal level at the receiver, the Relative Signal Strength Indicator (RSSI).

\section{The Number of Networks (ACCESs POINTS)}

Collecting statistics on the number of networks was produced in the movement of scanning all $2.4 \mathrm{GHz}$ range channels, with a period of 5 seconds. Average number of recorded by scanning access points was 24,7 .

Table I summarizes the overall results of the monitoring data. 
TABLE I. OVERALL RESULTS OF MONITORING OF ACCESS POINTS

\begin{tabular}{|c|c|c|}
\hline Parameter & $\begin{array}{c}\text { Measurement } \\
\text { units }\end{array}$ & Values \\
\hline The total number of scans & pcs & 1944 \\
\hline Interval of scanning & s & 5 \\
\hline $\begin{array}{c}\text { The total number of recorded } \\
\text { unique SSID }\end{array}$ & pcs & 4740 \\
\hline $\begin{array}{c}\text { The total number of recorded } \\
\text { unique MAC address }\end{array}$ & pcs & 5707 \\
\hline $\begin{array}{c}\text { The average number of access } \\
\text { points in the coverage area }\end{array}$ & pcs & 24,7 \\
\hline $\begin{array}{c}\text { The minimum number of } \\
\text { access points in the coverage } \\
\text { area }\end{array}$ & pcs & 1 \\
\hline $\begin{array}{c}\text { The maximum number of } \\
\text { access points in the coverage } \\
\text { area }\end{array}$ & pcs & 79 \\
\hline $\begin{array}{c}\text { The mean-square deviation of } \\
\text { the number of access points in } \\
\text { the coverage area }\end{array}$ & pcs & 15,3 \\
\hline $\begin{array}{c}\text { The average residence time in } \\
\text { the access point coverage area }\end{array}$ & s & 21,7 \\
\hline
\end{tabular}

Figure I shows a graph of changing the number of access points within range of the time (moving device).

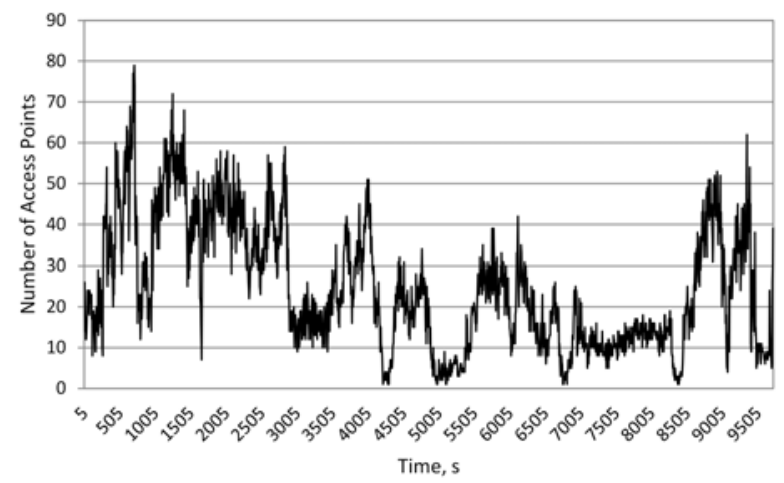

FIGURE I. CHANGING THE NUMBER OF ACCESS POINTS IN THE RECEPTION AREA WHEN PASSING ROUTE.

The empirical distribution of the number of access points in the coverage area is shown in Figure II.

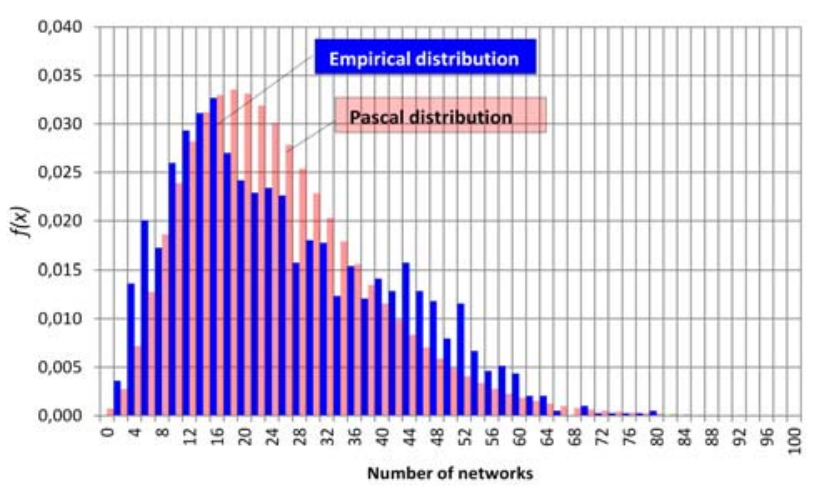

FIGURE II. PROBABILITY DISTRIBUTION NUMBER OF NETWORKS.

Empirical distribution approximated distribution Pascal (negative binomial distribution) [16].

$$
P_{k}(r, p)=C_{k+r-1}^{k} p^{r}(1-p)^{k}
$$

Distribution parameters $r=4, p=0,139$.

This result can be interpreted as follows. If the access points are uniformly distributed throughout, ie they form a Poisson field and the reception area is a circle or other geometric shape [17], the probability of finding $\mathrm{k}$ points of access in the reception area to obey the Poisson distribution

$$
P_{k}(\alpha)=\frac{(\lambda)^{k}}{k !} e^{-\lambda}
$$

with parameter equal to $\lambda=\rho S$ where $\rho$ - density of access points, and $S$ - the acquisition zone.

However, if the parameter $\lambda$ is random and is distributed according to a gamma distribution with parameters $r$ and $p$ [16], the number of access points are distributed according to a negative binomial distribution (1). In this case $\lambda$ parameter is determined by the density and area of the access point coverage area. Area coverage area depends on random factors affecting the level of the received radio signal. Thus, the parameter $\lambda$ is accidental, resulting in a difference between the obtained distribution of the Poisson distribution.

According to the number of detections of multiple access points in the input area, estimation of the residence time in the access point coverage area can be constructed. The probability distribution of the residence time Access Point in the reception area is shown on Figure III.

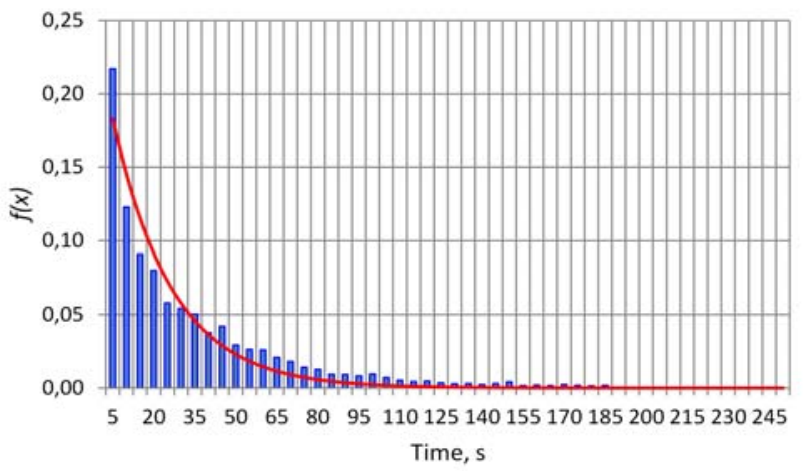

FIGURE III. THE RESIDENCE TIME IN THE ACCESS POINT COVERAGE AREA.

Empirical distribution is approximated by an exponential distribution:

$$
f(t, \alpha)=\frac{1}{\alpha} e^{-\frac{1}{\alpha} x}
$$

where the parameter distribution $\alpha=21,7 \mathrm{~s}$.

\section{USING THE CHANNEL}

The overall results of monitoring the usage of channels are shown in Table II. 
TABLE II. OVERALL RESULTS OF THE MONITORING THE USAGE OF CHANNELS

\begin{tabular}{|c|c|c|}
\hline Parameter & $\begin{array}{l}\text { Measurement } \\
\text { units }\end{array}$ & Values \\
\hline Interval of scanning & s & 2988 \\
\hline $\begin{array}{c}\text { The total number of recorded } \\
\text { frame }\end{array}$ & pcs & 150451 \\
\hline $\begin{array}{l}\text { The total data volume in the } \\
\text { observed frames }\end{array}$ & Mbyte & 33,99 \\
\hline $\begin{array}{l}\text { The average frames rate in the } \\
\text { channel }\end{array}$ & fps & 50,4 \\
\hline $\begin{array}{l}\text { The standard deviation of } \\
\text { frames rate in the channel }\end{array}$ & fps & 37,6 \\
\hline $\begin{array}{l}\text { Minimum frames rate in the } \\
\text { channel }\end{array}$ & fps & 0 \\
\hline $\begin{array}{c}\text { Maximum frames rate in the } \\
\text { channel }\end{array}$ & fps & 578 \\
\hline The average size of the frame & byte & 237 \\
\hline $\begin{array}{c}\text { Average traffic rate in the } \\
\text { channel }\end{array}$ & $\mathrm{kbit} / \mathrm{s}$ & 11,65 \\
\hline $\begin{array}{l}\text { The standard deviation of the } \\
\text { traffic rate in the channel }\end{array}$ & $\mathrm{kbit} / \mathrm{s}$ & 14,98 \\
\hline $\begin{array}{l}\text { Maximum traffic rate in the } \\
\text { channel }\end{array}$ & Mbit/s & 2,54 \\
\hline $\begin{array}{c}\text { Minimum traffic rate in the } \\
\text { channel }\end{array}$ & $\mathrm{bit} / \mathrm{s}$ & 0 \\
\hline The average value of RSSI & $\mathrm{dBm}$ & $-85,46$ \\
\hline $\begin{array}{c}\text { The standard deviation of the } \\
\text { RSSI }\end{array}$ & $\mathrm{dBm}$ & 3,90 \\
\hline The minimum value of RSSI & $\mathrm{dBm}$ & $-97,00$ \\
\hline The maximum value of RSSI & $\mathrm{dBm}$ & $-54,69$ \\
\hline
\end{tabular}

Figure IV shows the empirical distribution of frame rate and an approximation of Pascal distribution (1). The distribution form of frames rate is close to the distribution shape of the number of access points (Figure II).

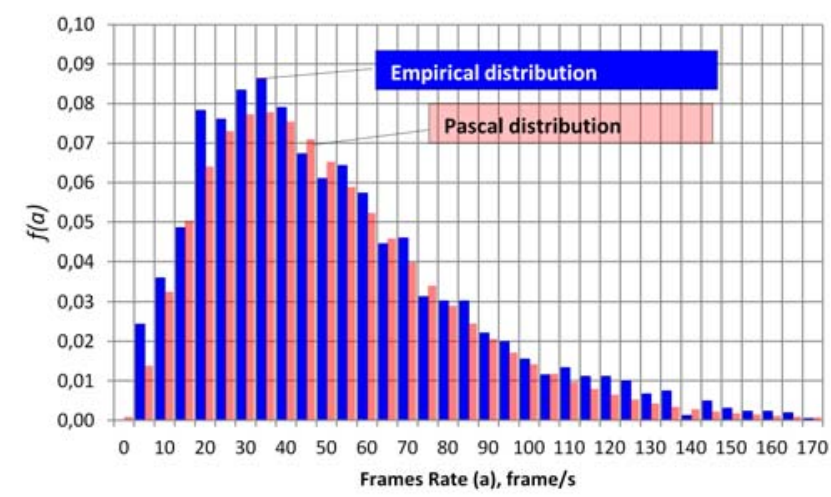

FIGURE IV. DISTRIBUTION OF FRAMES RATE.

Distribution parameters $r=3, p=0,056$.

Figure $\mathrm{V}$ shows the empirical distribution of traffic rate and an approximation of gamma distribution [16].

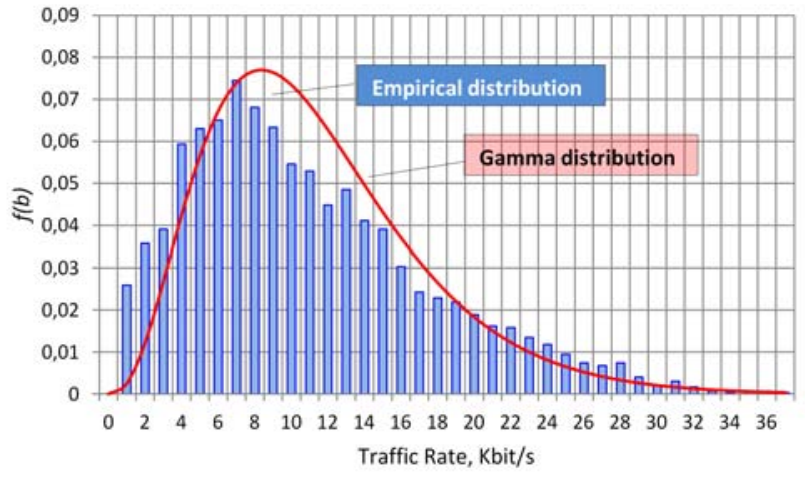

FIGURE V. DISTRIBUTION OF TRAFFIC RATE.

Gamma distribution

$$
f(x, k, \beta)=\frac{x^{\alpha-1}}{\beta^{\alpha} \Gamma(\alpha)} e^{-\frac{x}{\beta}}
$$

Distribution parameters $\alpha=3100, \beta=3,76$.

Figure VI shows the distribution of the average rate of received frames on channels range $2.4 \mathrm{GHz}$ standard IEEE $802.11 \mathrm{~b} / \mathrm{g} / \mathrm{n}$.

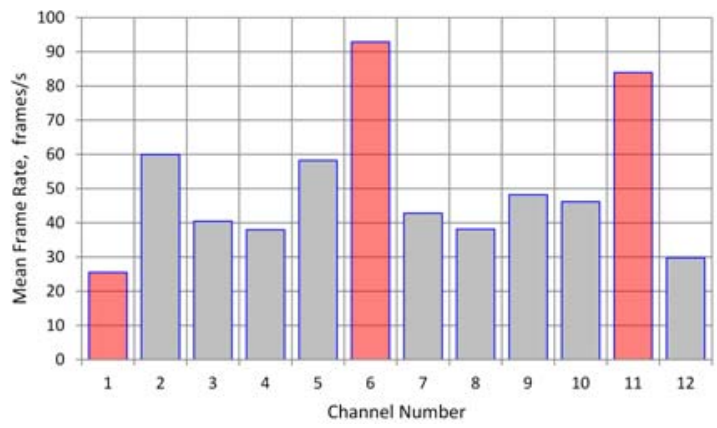

FIGURE VI. DISTRIBUTION OF THE RECEIVING FRAMES RATE ON CHANNELS RANGE 2.4 GHZ STANDARD IEEE $802.11 \mathrm{~b} / \mathrm{g} / \mathrm{n}$.

As seen from this diagram, the maximum rate of frames occurs in the channels 6, 11 and 1 in decreasing order of the evaluated values. This result is somewhat expected because most of devices (acting as access points) use these channels as the most spread between each other in frequency. The greatest value of the average rate of frames occurs in a channel with a 6 number. The maximum registered value during the observation for this channel totaled 578 frames/s, minimum 8 frames/s.

Figure VII shows the distribution of the values of the RSSI indicator. 


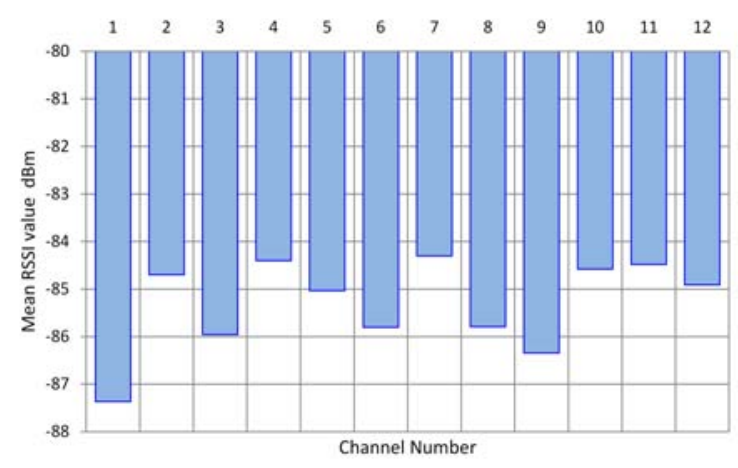

FIGURE VII. DISTRIBUTION OF AVERAGE RSSI ON CHANNELS RANGE OF 2.4 GHZ IEEE $802.11 \mathrm{~b} / \mathrm{g} / \mathrm{n}$ STANDARD.

From Figure VII it is seen that there is no obvious dependence of the average level of the received signal from the channel number. The minimum value of the average reception level takes place on the first channel. Comparing the data of Fig. VI and Fig. VII, it can be assumed that the low RSSI level and the low frames rate compared to channels 6 and 11 , are due to unevenness of receiver characteristics to the lower limit range.

Figure IIX shows a graph of change RSSI values during monitoring.

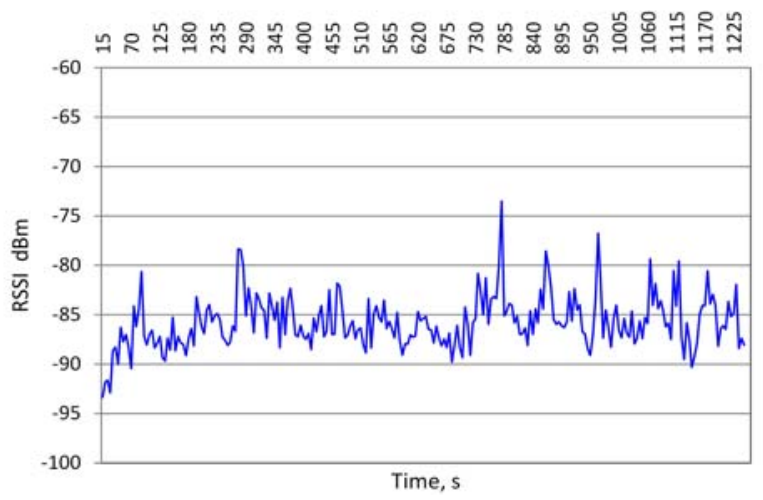

FIGURE VIII. CHANGING THE RSSI VALUE DURING THE MONITORING TIME.

Figure IX shows the empirical distribution of RSSI indicator values.

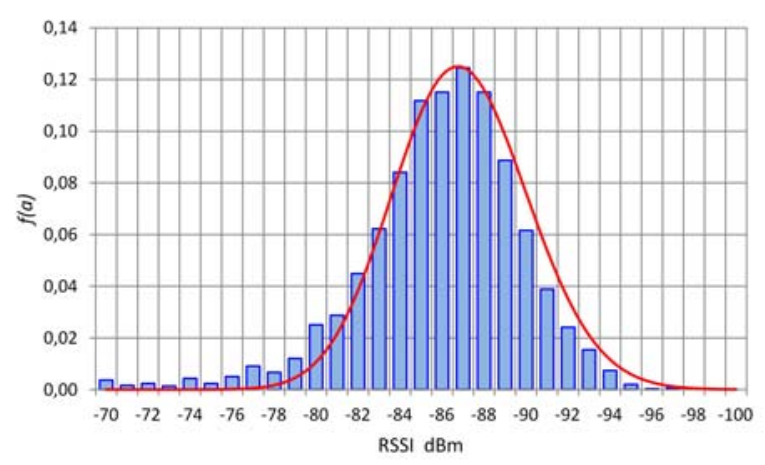

FIGURE IX. DISTRIBUTION OF THE RSSI INDICATOR VALUES.
The figure shows the empirical distribution and its approximation of Nakagami distribution [12]

$$
f(x, \mu, \omega)=\frac{2 \mu^{\mu}}{\Gamma(\mu) \omega^{\mu}} x^{2 \mu-1} e^{-\frac{\mu}{\omega} x^{2}}
$$

Distribution parameters $\mu=18, \omega=184$.

\section{CONCLUSION}

1. The results of the collection and analysis of statistical data showed that 2.4 GHz IEEE 802.11 family of standards in urban dense environment there is a sufficiently large number of potential sources of traffic (access points). Their average number in the availability area at an arbitrary point of placing transceiver is 24,7 .

2. When moving the receiver with an average speed of 3.8 $\mathrm{m} / \mathrm{s}$, the number of access points in the reception area (with the received signal level RSSI is not lower than $-100 \mathrm{dBm}$ ) is the probability distribution is close to the distribution of the Pascal (negative binomial distribution).

3. The residence time in the zone of the access point of the movable receiving device (with an average speed of $3.8 \mathrm{~km} / \mathrm{h}$ ) is distributed according to the law which is close to the exponential law, the average value was 35,2 s.

4. The distribution of frame rate in the monitoring zone was close to the law of Pascal distribution. The average value of frame rate was 50.4 frames/s. The maximum frame rate was 578 frames/s.

5 . The average value of the traffic rate on the monitoring results was $11.65 \mathrm{~Kb} / \mathrm{s}$, the maximum value - $2.54 \mathrm{Mb} / \mathrm{s}$. These results indicate a relatively low use of the channel. The maximum obtained value is equivalent to the traffic generated by a single video stream.

6. Average frame size was 237 bytes. This result is based on the fact that the average rate of the frames is based on the access point is 24.49 frames/s, indicates that a significant proportion of the traffic (about 40\%) of the service traffic.

7. The level of the received signal from the sources of traffic (estimated indicator RSSI) has a distribution close to Nakagami distribution. The average value of RSSI was 85.46 $\mathrm{dBm}$.

Summarizing the results, it can be concluded that the state of IEEE 802.11 standards family channels in the $2.4 \mathrm{GHz}$ band is characterized by a considerable presence of devices operating in this range. The probability of hitting a coverage area at least one device is close to 1 . However, the use of the channels of this range is relatively low, a large proportion of the traffic is service data of the IEEE 802.11 protocols. Thus, the probability of a channel overload with an exterior traffic is sufficiently small and this range can be used for communication between objects in a robotic system in urban dense environment. 


\section{ACKNOWLEDGMENT}

The work is supported by the Russian Ministry of Education in the framework of the Federal Target Program "Research and development on priority directions of scientifictechnological complex of Russia for 2014-2020" on the project "Development of methods and algorithms for adaptive motion control of multi spherical robots increased maneuverability in the face of uncertainty and significant external disturbances" (unique identifier project RFMEFI61315X0047).

\section{REFERENCES}

[1] D. Milutinovic, and J. Rosen, Redundancy in Robot Manipulators and Multi-Robot Systems. Springer, 2013.

[2] S. Grzonka, G.Grisetti, and W. Burgard, "A Fully Autonomous Indoor Quadrotor,” IEEE Transactions on Robotics, vol.28, pp. 90-100, February 2012.

[3] Y. Kantaros, M.M. Zavlanos, "Global Planning for Multi-Robot Communication Networks in Complex Environments," IEEE Transactions on Robotics, vol.32, pp. 1045-1061, October 2016.

[4] I.A. Zikratov, I.S. Lebedev, A.V. Gurtov, "Trust and Reputation Mechanisms for Multi-agent Robotic Systems," Lecture Notes in Computer Science, vol. 8638, pp. 106-120, 2014.

[5] A. Koucheryavy, A. Vladyko, R. Kirichek, "State of the Art and Research Challenges for Public Flying Ubiquitous Sensor Networks," Lecture Notes in Computer Science, vol. 9247, pp.299-308, 2015.

[6] J. Wang, S. Premvuti, A. Tabbara, "A wireless media access protocol (CSMA/CD-W) for mobile robot based distributed robotic systems," Proc. IEEE ICRA, pp. 2561-2566, 1995.

[7] D. Johnson, T. Stack, R. Fish, D.M. Flickinger, L. Stoller, R. Ricci, J. Lepreau, "Mobile Emulab: A Robotic Wireless and Sensor Network Testbed,” Proc. IEEE INFOCOM, pp. 1-12, 2006.

[8] R. Kirichek, "The Model of Data Delivery from the Wireless Body Area Network to the Cloud Server with the Use of Unmanned Aerial Vehicles,” Proc. ECMS, pp. 603-606, 2016.

[9] R. Kirichek, A. Paramonov, A. Koucheryavy, "Swarm of Public Unmanned Aerial Vehicles as a Queuing Network," Communications in Computer and Information Science, vol. 601, pp. 111-120, 2016.

[10] P. Shilin, R. Kirichek, A. Paramonov, A. Koucheryavy, "Connectivity of VANET Segments Using UAVs,” Lecture Notes in Computer Science, vol. 9870, pp. 492-500, 2016.

[11] A. Muthanna, P. Masek, J. Hosek, R. Fujdiak, O. Hussein, A Paramonov, A. Koucheryavy, "Analytical Evaluation of D2D Connectivity Potential in 5G Wireless Systems," Lecture Notes in Computer Science. vol. 9870. pp. 395-403, 2016.

[12] H. Suzuki, “A Statistical Model for Urban Radio Propagation,” IEEE Transactions On Communications, vol. 25, pp. 673-680, July 1977.

[13] ESP8266EX Datasheet, ver.1.0. Espressif, 2016. Available: https://www.espressif.com/sites/default/files/0aesp8266ex_datasheet_en_1.pdf

[14] ESP8266 Technical Reference, ver.1.2. Espressif, 2016. Available: https://espressif.com/sites/default/files/documentation/esp8266technical_reference_en.pdf

[15] ESP8266 Non-OS SDK API Reference, ver.2.0.0. Espressif, 2016. Available: https://espressif.com/sites/default/files/documentation/2cesp8266_non_os_sdk_api_reference_en.pdf

[16] M.G. Kendall, and A. Stuart, Advanced Theory of Statistics, vol.1, 2nd ed. London: Charles Griffin \& Company Limited, 1968.

[17] W. Feller, An Introduction to Probability Theory and Its Applications, vol. 1, 3rd ed. Wiley, 1968. 